\title{
Optimizing the ultrasonic-assisted extraction of antioxidants from Ulva lactuca algal biomass using factorial design
}

\author{
Sayed Rashad ${ }^{1} \cdot$ Ghadir El-Chaghaby $^{1} \cdot$ Eder C. Lima $^{2} \cdot$ Glaydson Simoes dos reis $^{3}$ (D)
}

Received: 8 February 2021 / Revised: 27 March 2021 / Accepted: 12 April 2021

(C) The Author(s) 2021

\begin{abstract}
Ultrasonic-assisted extraction (UAE) is increasingly emerging as a highly effective extraction technique. This extraction technique is affected by several experimental factors. The present work aimed to optimize the ultrasonic-assisted extraction of antioxidants from Ulva lactuca (sea lettuce), widespread macroalgae growing along the Mediterranean coast. In this respect, a full-factorial design $\left(2^{3}\right)$ was employed to assess the effect of three different factors at two levels and their interactions on the extraction of antioxidants from sea lettuce algal biomass. The studied factors were extraction solvent, time of extraction, and temperature. The two levels chosen for extraction solvent were $100 \%$ ethanol and $50 \%$ ethanol, for the sonication time $(1 \mathrm{~h}$ and $3 \mathrm{~h})$ and temperature $\left(25^{\circ} \mathrm{C}\right.$ and $\left.40{ }^{\circ} \mathrm{C}\right)$. All experiments were done using an ultrasonic bath, and the biomass to solvent ratio was kept at 1:5. Total antioxidant capacity and quercetin concentration were set as the two responses for optimum output. The results showed that the temperature and solvent were the dominating factors that significantly affect the extraction process. The optimum extraction parameters were extraction time of $1 \mathrm{~h}, 50 \%$ ethanol, and temperature of $25^{\circ} \mathrm{C}$. Under these conditions, the maximum value for TAA was calculated as $2166.51 \mathrm{mg}$ of ascorbic acid equivalent per gram ( $\mathrm{mg} / \mathrm{g}$ of AAE), and quercetin showed a maximum calculated value of $42.5 \mathrm{mg} / \mathrm{g}$ with combined desirability of 0.91 for the two responses. The present study results indicate that $U$. lactuca can be used as a source of antioxidants and phenolic compounds that can be applied in food and medicine at optimum extraction conditions.
\end{abstract}

Keywords Ulva lactuca · Ultrasonic extraction · Antioxidant · Quercetin · Factorial design

\section{Introduction}

The extraction of bioactive compounds from different biomass types is nowadays of rising interest to researchers in their attempt to find natural alternatives to chemical compounds, especially those used in food and pharmaceuticals. Extraction is critical in the recovery of phytochemicals from plant matrix and biomasses $[1,2]$. Several sorts of extraction techniques are found: maceration, supercritical fluid extraction, percolation, microwave-

Glaydson Simoes dos reis

glaydsonambiental@gmail.com; glaydson.simoes.dos.reis@slu.se

1 Regional Center for Food and Feed, Agricultural Research Center, Giza, Egypt

2 Institute of Chemistry, Federal University of Rio Grande do Sul, Porto Alegre, RS, Brazil

3 Department of Forest Biomaterials and Technology, Biomass Technology Centre, Swedish University of Agricultural Sciences, SE-901 83 Umeå, Sweden assisted extraction, soxhlet extraction, and ultrasonic-assisted extraction (UAE) [1].

Compared to the conventional extraction techniques, the extraction assisted by UAE is an efficient method because it can reduce the working time and use of solvents, simplify its operation and work-up, and yield a final product with high quality [1, 2]. In addition, UAE can be performed at low temperatures, which reduces the heat loss caused by high temperatures and prevents the preservation of biologically active substances [1-3]. For instance, some reports investigated the use of UAE to extract polysaccharides from different plant materials, and the results showed that the extraction time was significantly reduced and also improved overall targeted compound extraction yield relative to traditional methods [2-4].

The extraction assisted by ultrasound has proved to enhance the extraction by the passage of ultrasonic waves in the solvent, allowing greater solvent penetration into the sample matrix, increasing the contact surface area between solid and liquid phase [5]. During ultrasonic-assisted extraction, some variables directly affecting the extraction efficiency, such as the extraction time, temperature, solvent concentration, and type of solvent [6]. 
Conventionally, in order to study the effect of different parameters on extraction efficiency, each of the parameters was varied at different levels in separate experiments using a one-factor-at-atime process that is disadvantageous and time-consuming [7].

These variables play an essential role in extraction efficiency. However, it is hard to quantify how much and in which way (positively or negatively) these variables affect the extraction process [8]. In this sense, the use of the design of experiment (DOE) is a beneficial and trustful way to determine the significant variables affecting the UAE process [9]. DOE offers the advantages of acquiring much information and reaching the optimum conditions within minimum time and fewer experiments $[1,10]$. DOE was successfully employed for optimizing the extraction of antioxidants and bioactive compounds from plants, agricultural residues, byproducts, algal biomass, plant biomass, and others $[8,11]$.

Several studies have shown that algal biomass has many phytochemicals and has several bioactivity types $[12,13]$. Ulva lactuca (sea lettuce) is a widespread macroalga among many seaweeds growing along the Mediterranean coast in Egypt, particularly in Alexandria [14]. This marine alga is rich in several bioactive compounds with potent nutraceutical properties [15]. Ulva lactuca was found to contain polyphenols and flavonoids that can act as antioxidants, anticancer, and anti-inflammatory. Quercetin, kaempferol, gallic acid, and rutin have been identified among the flavonoids in Ulva lactuca extracts [16, 17]. To the best of our knowledge, no study on optimizing antioxidants' extraction (antioxidant capacities and quercetin concentrations) from Ulva lactuca using DOE has been reported yet.

This work's objective was to use a DOE to optimize the extraction of antioxidant compounds from Ulva lactuca biomass by using an ultrasonic-assisted extraction process. A full-factorial design was used to demonstrate the relative importance of extraction variables and responses. The three variables were evaluated (extraction solvent, time, and temperature) on two responses, antioxidant capacity and quercetin concentration of the obtained extracts.

\section{Materials and methods}

\subsection{Algae biomass}

Sea lettuce (Ulva lactuca) algae were collected from Abu Qir Bay east of Alexandria, Egypt, and were washed at the collection site before transferred to the laboratory. The samples were morphologically identified according to the relevant literature adopted by Aleem [18]. The algae were then washed with deionized water and then oven-dried at $40{ }^{\circ} \mathrm{C}$ to constant weight. After dried, the biomass was ground using an electric blender.

\subsection{Ultrasonic-assisted extraction procedure}

A full-factorial $2^{3}$ design was used for the optimization of the ultrasonic-assisted extraction process. The three factors chosen were varied at two levels: $(-1)$ and $(+1)$ for low and high levels.

Table 1 shows the factors, their levels, and codes used in the statistical model.

During all experiments, the biomass to solvent ratio was 1:5 $(\mathrm{w} / \mathrm{v})$, and the extractions were done in an ultrasonic bath with an ultrasonic frequency of $40,000 \mathrm{~Hz}$ and ultrasonic power of $60 \mathrm{~W}$. The samples were sonicated for the predetermined time, after which the mixtures were cooled to room temperature and then filtered through filter paper (Whatman no. 1) to remove solid debris.

The responses to variation in extraction factors used to build the model were the extracts' total antioxidant capacities (Y1) and their quercetin concentrations (Y2).

\subsection{Determination of total antioxidant capacity}

According to the method previously reported by Prieto et al. [19], the total antioxidant activity of the extracts was determined using the phospho-molybdenum method. For any sample solution $(0.1-0.5 \mathrm{~mL})$ was added $0.3 \mathrm{~mL}$ of phosphomolybdenum solution $\left(4 \mathrm{mmol} / \mathrm{L}\left(\mathrm{NH}_{4}\right)_{6} \mathrm{Mo}_{7} \mathrm{O}_{24} \cdot 4 \mathrm{H}_{2} \mathrm{O}, 28\right.$ $\mathrm{mmol} / \mathrm{L} \mathrm{Na}_{3} \mathrm{PO}_{4}$, and $0.6 \mathrm{~mol} / \mathrm{L} \mathrm{H}_{2} \mathrm{SO}_{4}$ ). The reactional mixture was incubated at $95{ }^{\circ} \mathrm{C}$ for $90 \mathrm{~min}$. The incubator was turned off, and the system was cooled down to room temperature. After it, the blue-colored complex was spectrophotometrically measured at $695 \mathrm{~nm}$, using a visible spectrophotometer. The antioxidant activity was expressed as milligrams of ascorbic acid equivalent per gram (mg/g AAE).

\subsection{Determination of quercetin concentration}

Quercetin concentration in the extracts was determined by HPLC (Agilent 1260) using a C18 column with an isocratic mixture of water and methanol plus $0.1 \% \mathrm{v} / \mathrm{v}$ of formic acid in the ratio of 20:80. The UV detector was set at $258 \mathrm{~nm}$, and the flow-rate was set at $0.4 \mathrm{~mL} / \mathrm{min}$ [20]. Quercetin standard (Sigma-Aldrich $99 \%$ purity) was used as a reference standard to get the calibration curve.

Table 1 Factors' levels and codes used in the statistical model

\begin{tabular}{llll}
\hline Factor & Code & Level $(-1)$ & Level $(+1)$ \\
\hline Extraction solvent & $\mathrm{A}$ & Ethanol (100\%) & Ethanol:water (50:50) \\
Time $(\mathrm{h})$ & $\mathrm{B}$ & 1 & 3 \\
Temperature $\left({ }^{\circ} \mathrm{C}\right)$ & $\mathrm{C}$ & 25 & 40 \\
\hline
\end{tabular}




\subsection{Statistical analysis}

The experiment was designed, and the results obtained were analyzed using Minitab 19 (Minitab Inc., State College, PA, USA) software. The regression equation and analysis of variance (ANOVA) were obtained, and a confidence interval of $95 \%$ was set to test the significant effect of the factors and their interaction.

\section{Results and discussion}

In the present study, a two-level full-factorial design was employed to evaluate the most critical parameters affecting the total antioxidant capacity (TAA) and quercetin concentration (quercetin) of Ulva lactuca extract. Based on several previous studies, "Querectin" was chosen as a representative example for the phenols present in Ulva lactuca extract [14, 21, 22]. The effects of three factors, the solvent (A), extraction time (B), and temperature (C), at two levels each. In this work, two independent responses were studied (TAA and quercetin content). The $2^{3}$ full-factorial design experiments with the coded factors and their respective responses are presented in Table 2. The factorial design's ANOVA results are presented in Table 3 (TAA) and Table 4 (quercetin).

The results of the regression equations based on the firstorder model with three parameters and their interaction terms for total antioxidant capacity and quercetin concentration were obtained as:

TAA $\quad 862.4-651.1$ Solvent -125.4 Temperature +61.1 Solvent * Time ++181.2 Time $*$ Temperature -161.0 Solvent $*$

Time $*$ Temperature

Quercetin 26.325-8.500 Solvent -2.300 Temperature 2.875 Solvent * Temperature
The terms with probability $(P)>0.05$ are not significant, and they were removed from the overall regression equation.

Table 3 shows that the temperature and solvent, the interactions of extraction time and temperature, and the interaction between the three factors (temperature, time, and solvent) have statistical significance on the total antioxidant capacity (TTA) of $U$. lactuca at the $95 \%$ confidence level. On the other hand, the impact of the time and other factor interactions (solvent * time and solvent * temperature) was not significant $(P>$ 0.05).

For quercetin concentration as a response (Table 4), it indicated a significant effect for the solvent and temperature and the interaction between solvent and temperature at the $95 \%$ confidence level. Notwithstanding, the effect of time as a single factor and the interactions of the factors (solvent $*$ time, time $*$ temperature, and solvent $*$ time $*$ temperature) were not significant $(P>0.05)$.

\subsection{Main and interaction effects}

Plots showing the main effects were obtained to determine these factors' effect on the response values (Fig. 1a and b). The plots gave the changes in both responses (TAA and quercetin) when the main factors' levels were altered from the low $(-1)$ to high levels $(+1)$. According to Nabgem et al. [23], as the line's slope becomes steeper than the non-altered graph, then the main effect's magnitude is greater. In Fig. $1 \mathrm{a}$ and b, the solvent level exerted the most significant effect on both responses (TAA and quercetin), and the low level for the solvent is more desirable to get higher TAA and quercetin. Thus, using ethanol (50\%) as extracting solvent leads to higher total antioxidant capacity and higher quercetin concentration in $U$. lactuca extract. The temperature level variation between $-1\left(25^{\circ} \mathrm{C}\right)$ and $+1\left(40^{\circ} \mathrm{C}\right)$ showed a low steep line that decreased when going from -1 to +1 , indicating higher total antioxidant capacity and higher quercetin concentration

Table 2 Full-factorial $2^{3}$ results

\begin{tabular}{|c|c|c|c|c|c|c|c|c|c|}
\hline \multirow[t]{2}{*}{ Run } & \multicolumn{3}{|c|}{ Coded factors } & \multicolumn{3}{|c|}{$\begin{array}{l}\text { Response } 1 \\
\text { TAA (mg/g AAE) }\end{array}$} & \multicolumn{3}{|c|}{$\begin{array}{l}\text { Response } 2 \\
\text { quercetin }(\mathrm{mg} / \mathrm{g})\end{array}$} \\
\hline & A & $\mathrm{B}$ & $\mathrm{C}$ & Read 1 & Read 2 & Mean & Read 1 & Read 2 & Mean \\
\hline 1 & 1 & 1 & 1 & 218.00 & 239.46 & 228.73 & 19.0 & 20.6 & 19.8 \\
\hline 2 & 1 & -1 & 1 & 128.76 & 129.18 & 128.97 & 16.0 & 18.0 & 17.0 \\
\hline 3 & -1 & -1 & 1 & 978.20 & 1112.7 & 1045.45 & 29.8 & 27.8 & 28.8 \\
\hline 4 & -1 & 1 & -1 & 1141.1 & 1453.1 & 1297.11 & 35.0 & 40.0 & 37.5 \\
\hline 5 & -1 & -1 & -1 & 2345.1 & 1987.9 & 2166.51 & 45.0 & 40.0 & 42.5 \\
\hline 6 & 1 & -1 & -1 & 273.36 & 195.36 & 234.36 & 16.0 & 19.0 & 17.5 \\
\hline 7 & 1 & 1 & -1 & 231.06 & 275.4 & 253.23 & 19.0 & 15.0 & 17.0 \\
\hline 8 & -1 & 1 & 1 & 1816.9 & 1273.3 & 1545.06 & 33.0 & 28.0 & 30.5 \\
\hline
\end{tabular}

A, solvent; $\mathrm{B}$, time; $\mathrm{C}$, temperature

$(-1)$ stands for the low, and (+1) stands for high levels 
Table 3 ANOVA results for total antioxidant capacity (TAA)

\begin{tabular}{llllll}
\hline Source & DF & Adj. SS & Adj. MS & $\begin{array}{l}F \text { - } \\
\text { value }\end{array}$ & $\begin{array}{l}P \text { - } \\
\text { value }\end{array}$ \\
\hline Model & 7 & $8,188,374$ & $1,169,768$ & 34.22 & 0.000 \\
Linear & 3 & $7,050,276$ & $2,350,092$ & 68.74 & 0.000 \\
Solvent & 1 & $6,783,004$ & $6,783,004$ & 198.41 & 0.000 \\
Time & 1 & 15,770 & 15,770 & 0.46 & 0.516 \\
Temperature & 1 & 251,502 & 251,502 & 7.36 & 0.027 \\
2-way interactions & 3 & 723,285 & 241,095 & 7.05 & 0.012 \\
Solvent * Time & 1 & 59,639 & 59,639 & 1.74 & 0.223 \\
Solvent * Temperature & 1 & 138,094 & 138,094 & 4.04 & 0.079 \\
Time * Temperature & 1 & 525,553 & 525,553 & 15.37 & 0.004 \\
3-way interactions & 1 & 414,813 & 414,813 & 12.13 & 0.008 \\
Solvent * Time * Temperature & 1 & 414,813 & 414,813 & 12.13 & 0.008 \\
Error & 8 & 273,493 & 34,187 & & \\
Total & 15 & $8,461,867$ & & & \\
\hline
\end{tabular}

that were obtained when the extraction temperature is $25^{\circ} \mathrm{C}$. On the other hand, Fig. $1 \mathrm{a}$ and $\mathrm{b}$ reveal that the variation in extraction time level is almost negligible, as shown from the flat line between -1 and +1 .

It has been demonstrated that using a mixture of ethanol and water appears to be the proper extraction solvent due to the different polarities of both solvents, the possibility of mixing them in any proportion, and their acceptability for human consumption [24]. In agreement with the results obtained during the present study, Zuorro and Lavecchia [25] reported that the solvent's composition greatly affects the extraction and found that using 60:40 ethanol-water mixture gave better results compared to pure ethanol or pure water. It was previously reported that water could swell the plant material and improve extractability by allowing the solvent to penetrate the solid matrix more easily; aqueous-alcoholic mixtures extract higher phenolic levels than other solvents [26].

As for the effect of temperature, the negative effect of the high level of temperature on TAA and quercetin could be attributed to the assumption that high temperature may cause degradation of the natural compounds in the extract, or loss of some compounds by volatilization, which will, in turn, result in a decrease in the activity of the extracts [27].

The time of ultrasonic extraction did not significantly affect TAA and quercetin extraction from U. lactuca. It is estimated that when using ultrasonic extraction, a short time is required, conversely to the case of extraction by maceration. Ultrasonication results in mechanical agitation, cavitation, and thermal effects, which improves the extraction process and release of bioactive compounds. However, it has been
Table 4 ANOVA results for quercetin concentration

\begin{tabular}{llllll}
\hline Source & DF & Adj. SS & Adj. MS & $\begin{array}{l}F \text { - } \\
\text { value }\end{array}$ & $\begin{array}{l}P \text { - } \\
\text { value }\end{array}$ \\
\hline Model & 7 & 1408.87 & 201.27 & 29.13 & 0.000 \\
Linear & 3 & 1240.89 & 413.63 & 59.86 & 0.000 \\
Solvent & 1 & 1156.00 & 1156.00 & 167.29 & 0.000 \\
Time & 1 & 0.25 & 0.25 & 0.04 & 0.854 \\
Temperature & 1 & 84.64 & 84.64 & 12.25 & 0.008 \\
2-way interactions & 3 & 165.09 & 55.03 & 7.96 & 0.009 \\
Solvent * Time & 1 & 7.84 & 7.84 & 1.13 & 0.318 \\
Solvent * Temperature & 1 & 132.25 & 132.25 & 19.14 & 0.002 \\
Time * Temperature & 1 & 25.00 & 25.00 & 3.62 & 0.094 \\
3-way interactions & 1 & 2.89 & 2.89 & 0.42 & 0.536 \\
Solvent * Time* Temperature & 1 & 2.89 & 2.89 & 0.42 & 0.536 \\
Error & 8 & 55.28 & 6.91 & & \\
Total & 15 & 1464.15 & & & \\
\hline
\end{tabular}


Fig. 1 a Main effects plot for TAA; $\mathbf{b}$ main effects plot for quercetin

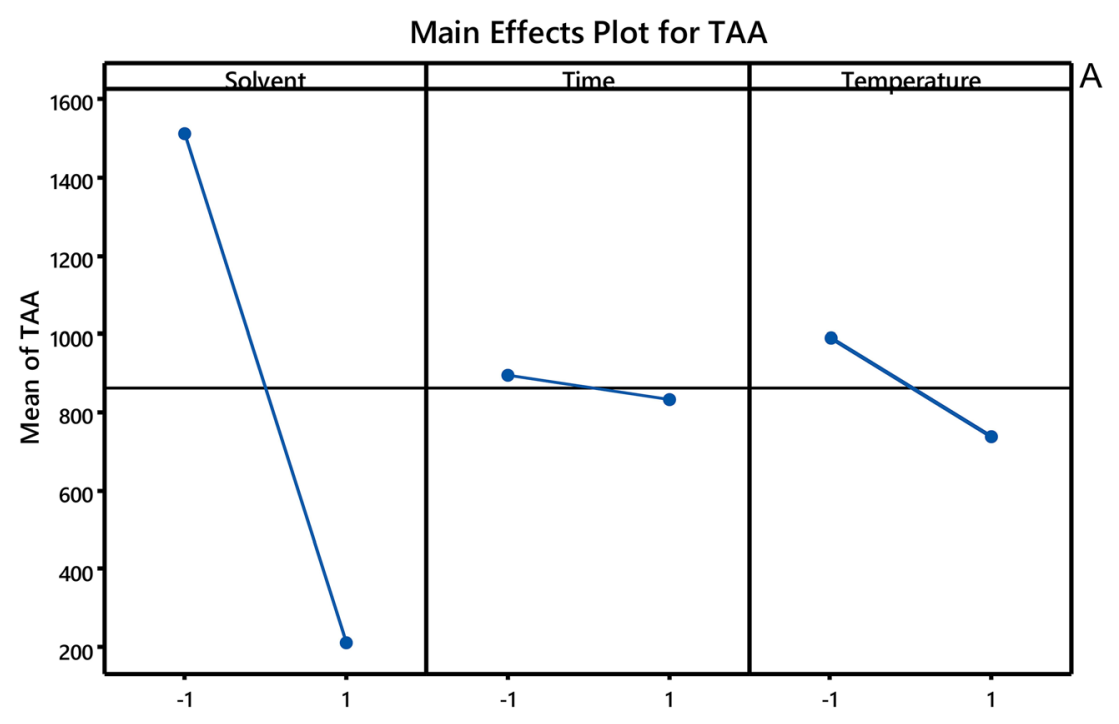

Main Effects Plot for Quercetin

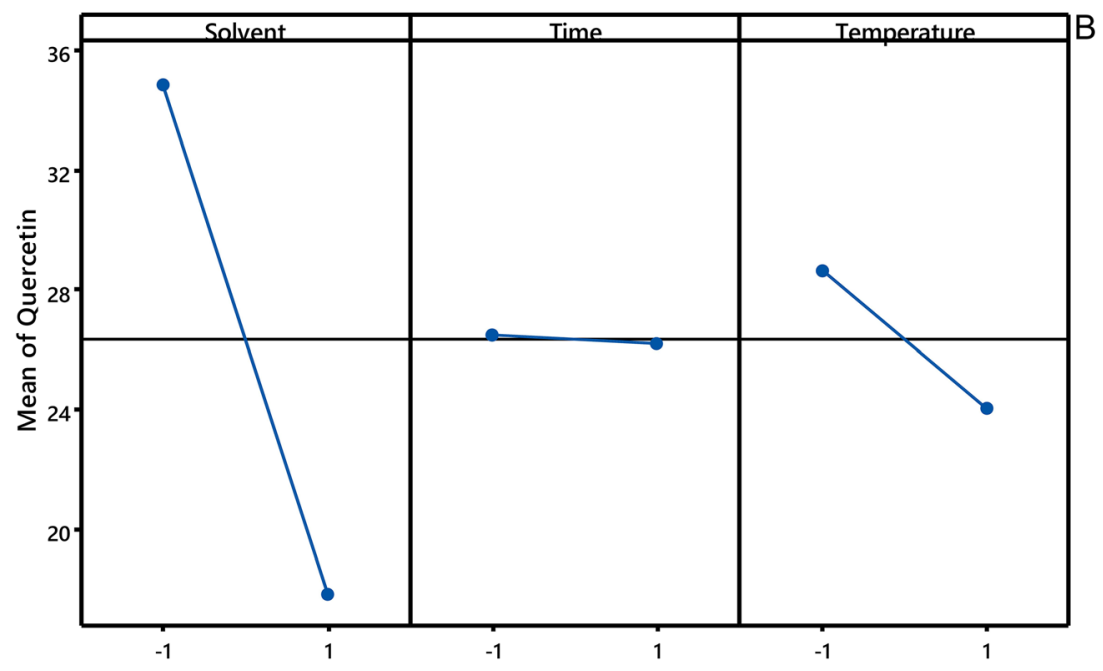

shown that long ultrasonic time could result in the degradation of phenolic compounds in the extracts [28].

According to Che Sulaiman et al. [29], biomass tissues weaken at high temperatures, and weak connections influence cell membranes. As a result, phenolic compounds can be extracted into the solvent with ease. On the other hand, a prolonged extraction time at high temperatures reduces the extraction yield since the elevated temperature allows the target compounds to oxidize and degrade.

After studying the main effects, the interaction plots were also obtained to evaluate every two parameters' interaction effects on TAA (Fig. 2a) and quercetin (Fig. 2b). An interaction between two factors is usually confirmed when the plot lines are not parallel [30]. From Fig. 2 a and $b$, the effect lines showed little intersect, indicating non-significant interactions between each pair of factors except for the interaction between temperature and time in case of TAA and interaction between the solvent and temperature in the case of quercetin.

The evaluation of each variable's effect on the two studied responses was also verified from the Pareto charts for TAA (Fig. 3a) and quercetin (Fig. 3b). This chart gives a representation of the absolute values of the main factors' effects and the interaction of these factors. The plot has a vertical reference line at the critical $t$-value that corresponds to a confidence level of $95 \%(\alpha=0.05)$; to show that the factors that surpass this line are significant [23]. The $t$-value was equal to 2.31 for both responses using a $95 \%$ confidence level and 8 degrees of freedom [30].

It can be noticed that the solvent was the main factor exerting the largest significant effect on the total 
Fig. 2 a Interaction plot for TAA; b interaction plot for quercetin
Interaction Plot for TAA

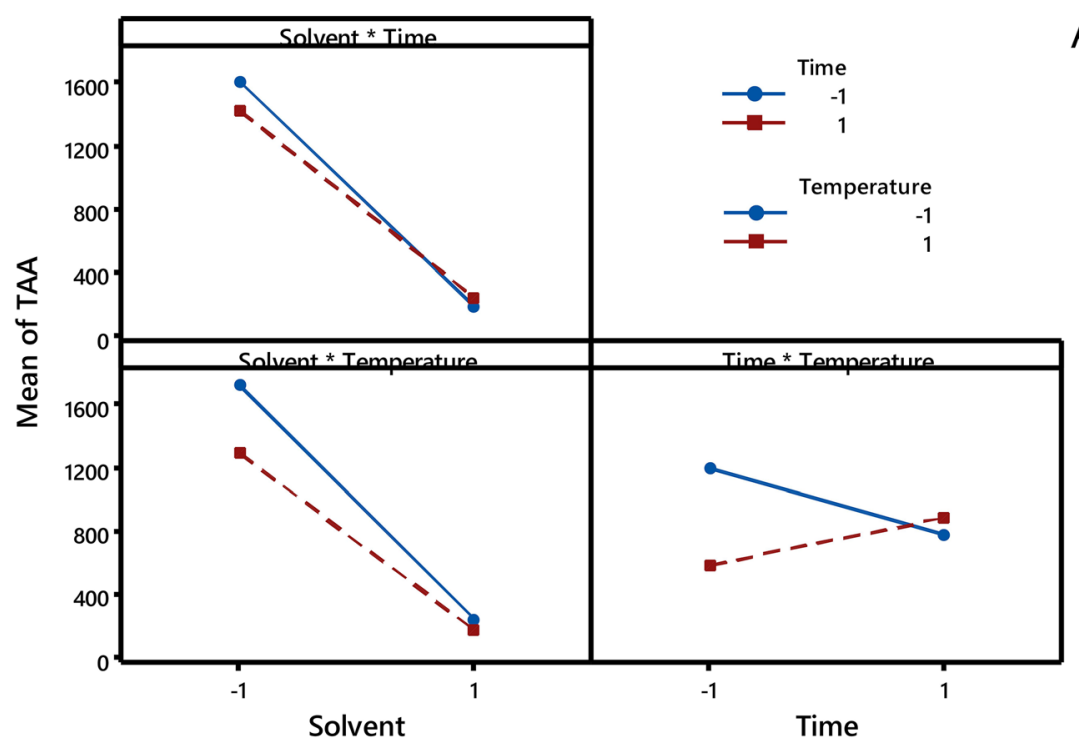

A

Interaction Plot for Quercetin

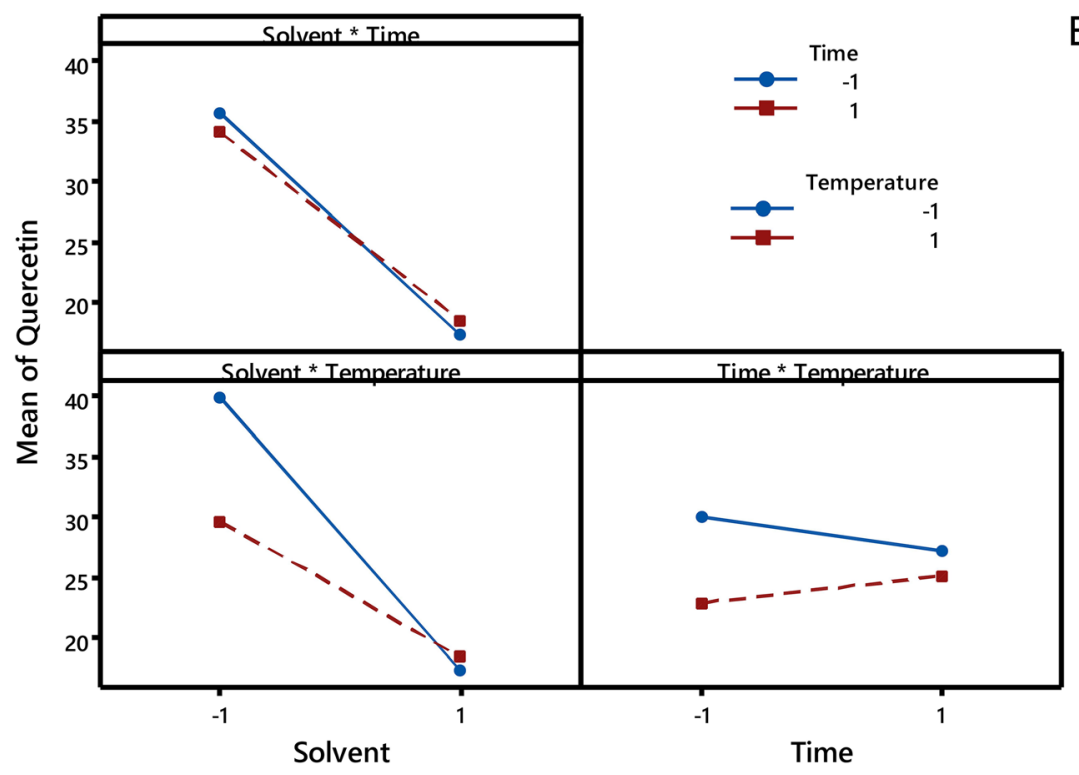

B

antioxidant capacity and also on quercetin concentration. From Fig. 3a, the two-way interaction between solvent and time had the second-most significant effect on TAA, followed by the three-way interaction between the factors. Fig. $3 \mathrm{~b}$ indicates that the interaction between temperature and solvent had the second-largest effect in quercetin concentration while the temperature effect was minimal. All other factors and interactions preceding the vertical line in the Pareto chart are considered non-significant.

\subsection{Contour plots}

Contour plots for optimized design space for ranges of all the three independent variables are shown in Fig. 4a for the response TAA and Fig. $4 \mathrm{~b}$ for the response quercetin. These plots are essential to show the relationship between the variables' main and interaction effects [23]. Figure $4 \mathrm{a}$ and $\mathrm{b}$ show the relative effects of any two variables on TAA and quercetin, respectively, while keeping the remaining variables constant. 
Fig. 3 a Pareto chart of standardized effects for TAA; $\mathbf{b}$ Pareto chart of standardized effects for quercetin
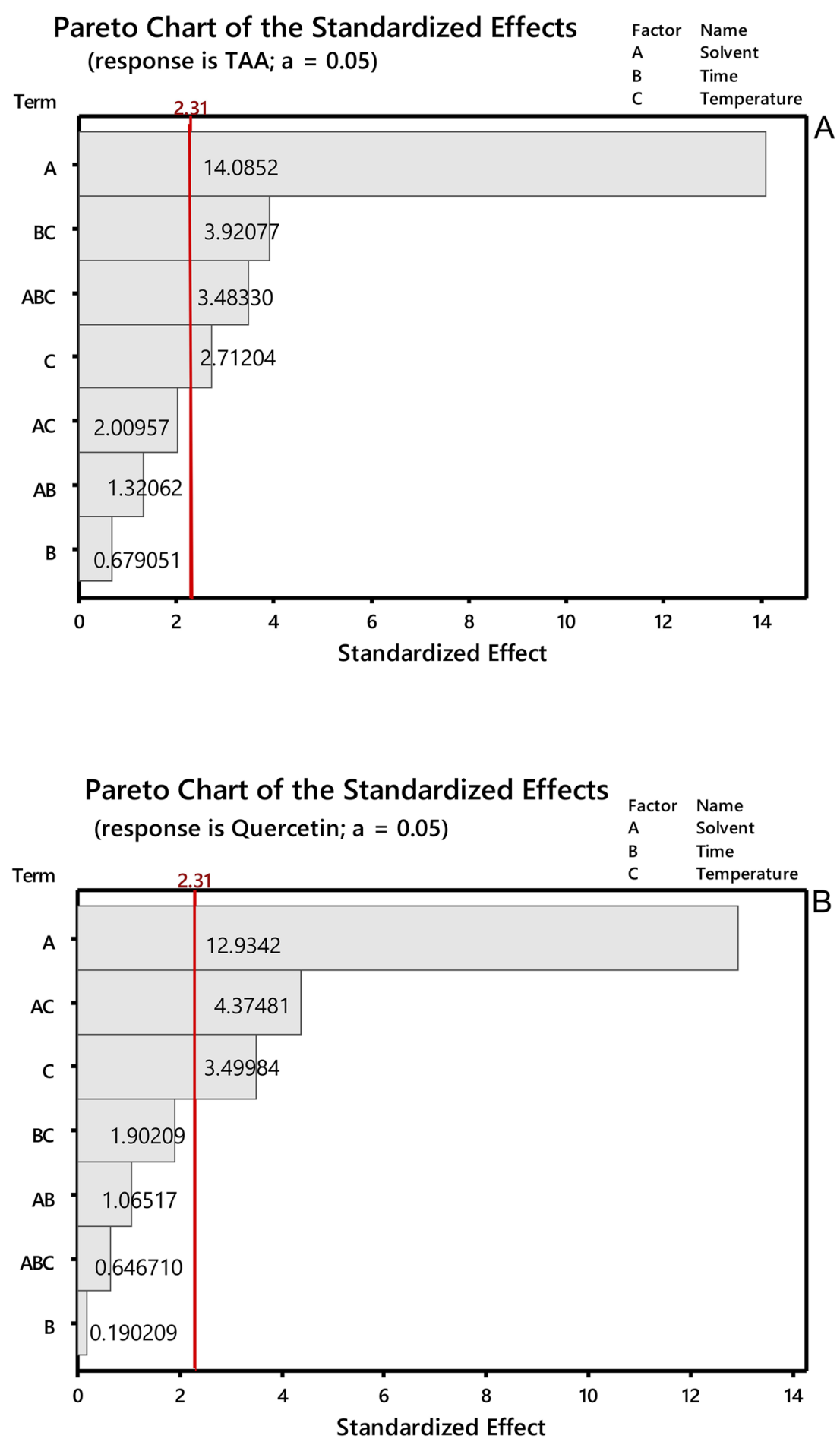

\subsection{Optimization of the process}

For the final optimization of the extraction process, a desirability function was applied to the experimental data, and the results are presented in Fig. 5. Primarily, each of the two responses TAA and quercetin was optimized individually. Results indicated that the maximum value for TAA was calculated as $2166.51 \mathrm{mg} / \mathrm{g}$ AAE, and this is achieved by keeping the three studied factors at their low level. On the other hand, the maximization of quercetin showed a calculated value of $42.5 \mathrm{mg} / \mathrm{g}$, and this also occurs by setting the studied factors at their low level. The combined desirability function for the two responses was 0.91 . Therefore, the optimum conditions for maximizing the extraction of total antioxidants and quercetin from $U$. lactuca are achieved employing ethanol (50\%) as extracting solvent and setting the temperature of extraction at $25{ }^{\circ} \mathrm{C}$ and keeping the extraction time $1 \mathrm{~h}$. 


\section{Contour Plots of TAA}
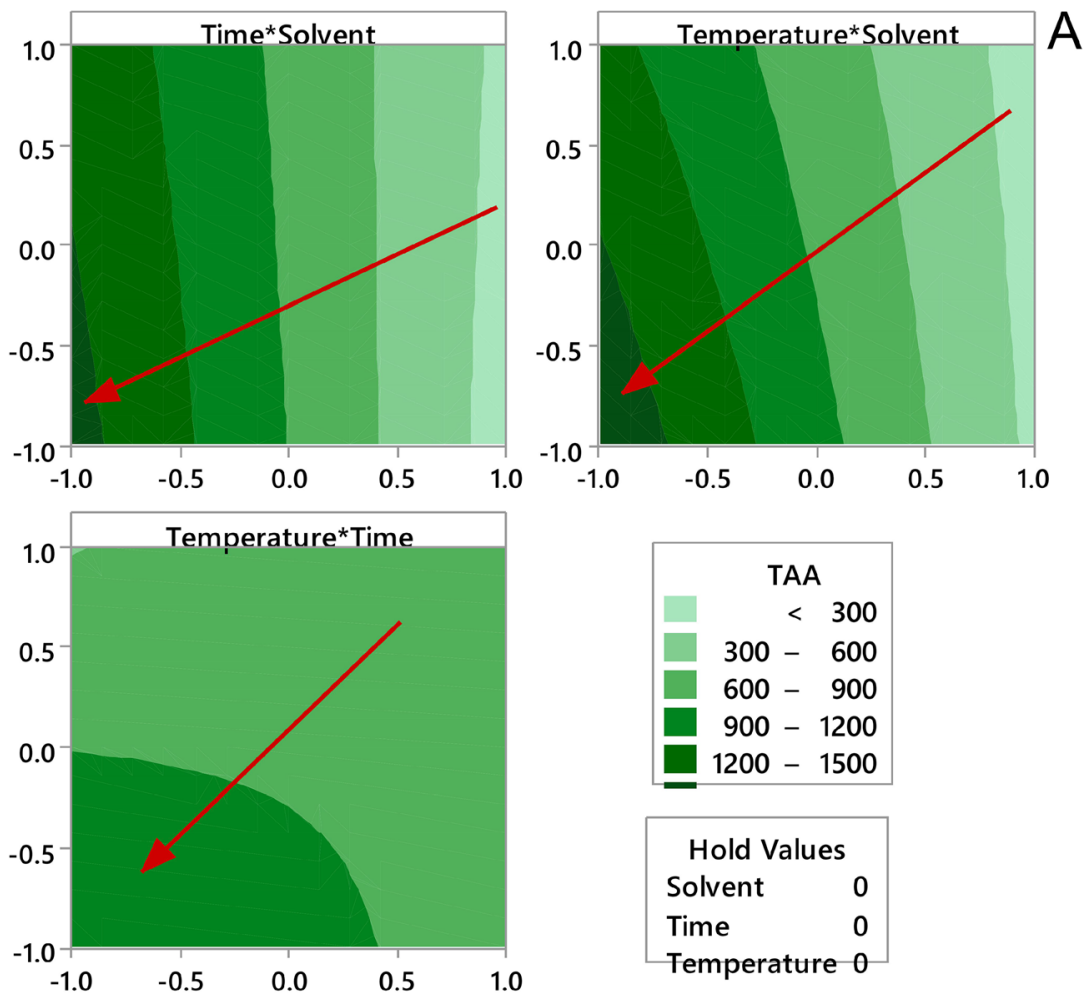

Hold Values Solvent 0

Time

Temperature 0

\section{Contour Plots of Quercetin}
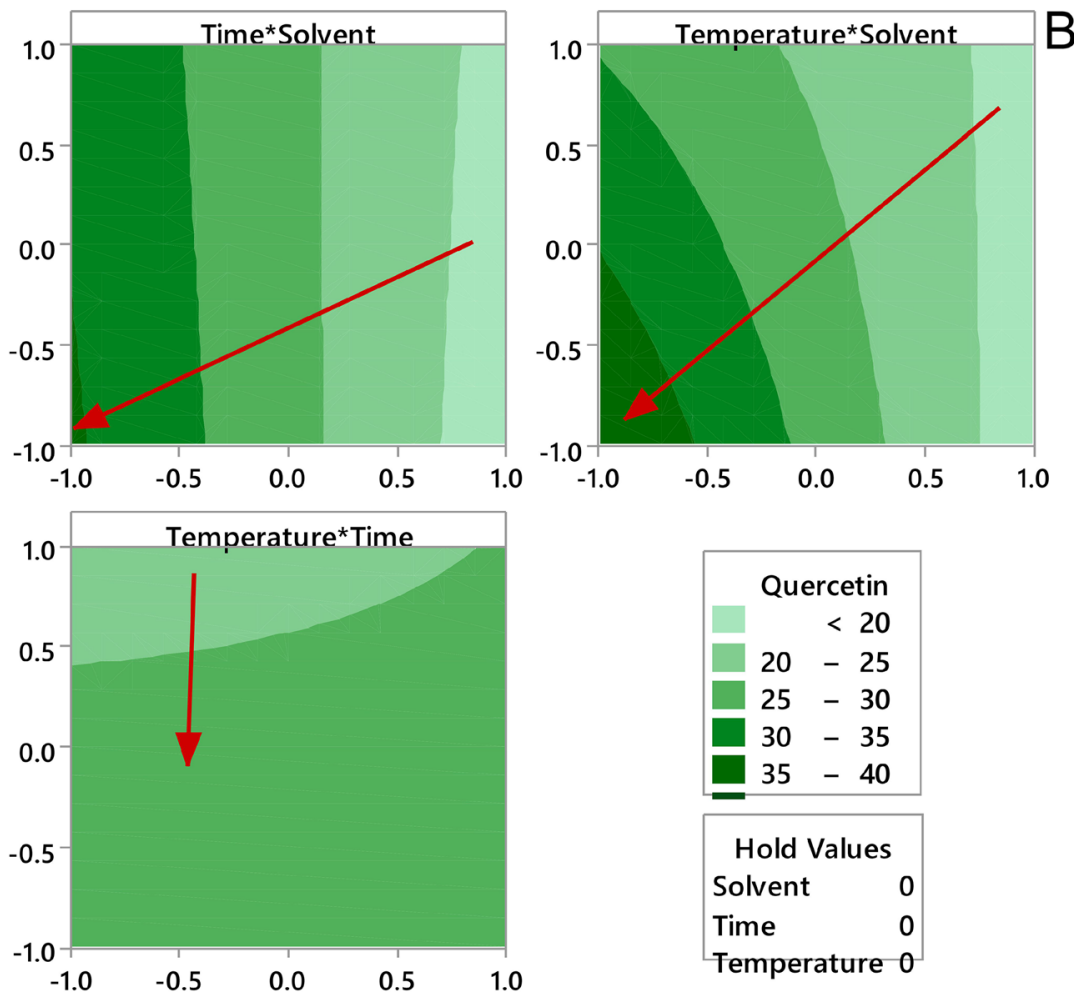

Fig. 4 a Contour plot for TAA; b contour plot for quercetin 


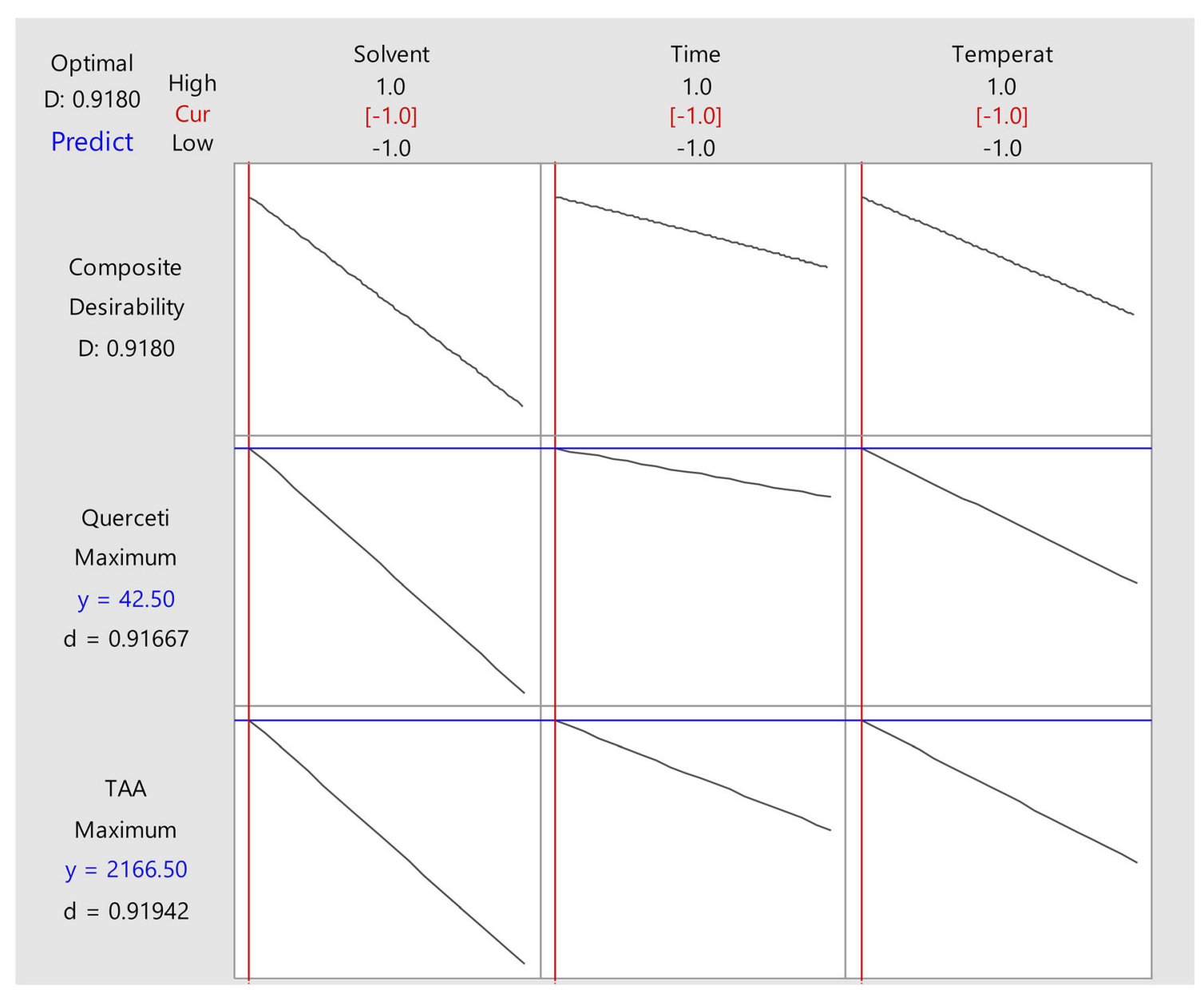

Fig. 5 Desirability plot for optimized responses

\section{Conclusions}

In this paper, a full-factorial design and ultrasonicassisted extraction were successfully employed for extracting antioxidants and quercetin from $U$. lactuca. The results showed that the optimum extraction parameters were extraction time of $1 \mathrm{~h}$, ethanol concentration of $50 \%$, and temperature of $25{ }^{\circ} \mathrm{C}$. Also, the data obtained herein indicated that $U$. lactuca extract has antioxidant activity and important phenolic compounds such as quercetin, and thus, this extract of algae can be considered a novel source of natural antioxidants. Natural antioxidants are highly desired for application in food industries as safer replacement to the synthetic antioxidants. In this respect, optimization of the extraction process is very important for industrial applications in order to achieve highest extraction within a short time, using less amount of solvent and low temperature to minimize costs and energy consumption.

Acknowledgements The authors wish to thank the Agricultural Research Center, Giza, Egypt, for facilitating the experimental work.
Funding Open access funding provided by Swedish University of Agricultural Sciences. Dr. Glaydson S. dos Reis is grateful to the Treesearch Postdoctoral program, Bio4Energy, a Strategic Research Environment appointed by the Swedish government, and the Swedish University of Agricultural Sciences for financial support. E. C. Lima thanks CNPq and FAPERGS for financial support.

Open Access This article is licensed under a Creative Commons Attribution 4.0 International License, which permits use, sharing, adaptation, distribution and reproduction in any medium or format, as long as you give appropriate credit to the original author(s) and the source, provide a link to the Creative Commons licence, and indicate if changes were made. The images or other third party material in this article are included in the article's Creative Commons licence, unless indicated otherwise in a credit line to the material. If material is not included in the article's Creative Commons licence and your intended use is not permitted by statutory regulation or exceeds the permitted use, you will need to obtain permission directly from the copyright holder. To view a copy of this licence, visit http://creativecommons.org/licenses/by/4.0/.

\section{References}

1. Pollini L, Tringaniello C, Ianni F, Blasi F, Manes J, Cossignani L (2020) Impact of ultrasound extraction parameters on the 
antioxidant properties of Moringa oleifera leaves. Antioxidants 9: 277. https://doi.org/10.3390/antiox 9040277

2. Prakash Maran J, Manikandan S, Thirugnanasambandham K, Vigna Nivetha C, Dinesh R (2013) Box-Behnken design-based statistical modeling for ultrasound-assisted extraction of corn silk polysaccharide. Carbohydr Polym 92:604-611. https://doi.org/10. 1016/j.carbpol.2012.09.020

3. Lee MH, Lin CC (2007) Comparison of techniques for extraction of isoflavones from the root of Radix Puerariae: ultrasonic and pressurized solvent extractions. Food Chem 105:223-228. https://doi. org/10.1016/j.foodchem.2006.11.009

4. Ahmad A, Alkharfy KM, Wani TA, Raish M (2015) Application of Box-Behnken design for ultrasonic-assisted extraction of polysaccharides from Paeonia emodi. Int J Biol Macromol 72:990-997. https://doi.org/10.1016/j.ijbiomac.2014.10.011

5. Ramić M, Vidović S, Zeković Z, Vladić J, Cvejin A, Pavlić B (2015) Modeling and optimization of ultrasound-assisted extraction of polyphenolic compounds from Aronia melanocarpa byproducts from filter-tea factory. Ultrason Sonochem 23:360-368. https://doi. org/10.1016/j.ultsonch.2014.10.002

6. Medina-Torres N, Ayora-Talavera T, Espinosa-Andrews H, Sánchez-Contreras A, Pacheco N (2017) Ultrasound-assisted extraction for the recovery of phenolic compounds from vegetable sources. Agronomy:7. https://doi.org/10.3390/agronomy7030047

7. Azubuike CC, Chikere CB, Okpokwasili GC (2016) Bioremediation techniques-classification based on site of application: principles, advantages, limitations and prospects. World J Microbiol Biotechnol 32:1-18. https://doi.org/10.1007/s11274-016-2137-x

8. Setyawan EI, Rohman A, Setyowati EP, Nugroho AK (2018) Application of factorial design on the extraction of green tea leaves (Camellia sinensis L.). J Appl Pharm Sci 8:131-138. https://doi. org/10.7324/JAPS.2018.8419

9. Lim MWS, Tan KM, Chew LY, Kong KW, Yan SW (2018) Application of two-level full factorial design for the extraction of fucoxanthin and antioxidant activities from Sargassum siliquosum and Sargassum polycystum. J Aquat Food Prod Technol 27:446463. https://doi.org/10.1080/10498850.2018.1448918

10. Tan I, Ahmad A, Hameed B (2008) Optimization of preparation conditions for activated carbons from coconut husk using response surface methodology. Chem Eng J 137:462-470. https://doi.org/10. 1016/j.cej.2007.04.031

11. Prasad KN, Kong KW, Ramanan RN et al (2012) Selection of experimental domain using two-level factorial design to determine extract yield, antioxidant capacity, phenolics, and flavonoids from Mangifera pajang Kosterm. Sep Sci Technol 47:2417-2423. https://doi.org/10.1080/01496395.2012.672511

12. El-Chaghaby GA, Rashad S, Abdel-Kader SF et al (2019) Assessment of phytochemical components, proximate composition, and antioxidant properties of scenedesmus obliquus, Chlorella vulgaris, and Spirulina platensis algae extracts. Egypt J Aquat Biol Fish 23. https://doi.org/10.21608/ejabf.2019.57884

13. Rashad S, El-Chaghaby GA, Elchaghaby MA (2019) Antibacterial activity of silver nanoparticles biosynthesized using spirulina platensis microalgae extract against oral pathogens. Egypt J Aquat Biol Fish 23. https://doi.org/10.21608/ejabf.2019.65907

14. Ghareeb DA, Zaatout HH, Ismael A, Abd-Elgwad A (2019) Phytochemical, antioxidant and anti-inflammatory screening of the Egyptian Ulva lactuca methanolic extract. Rec Pharm Biomed Sci 3:33-38

15. Delgado-Roche L, Rodeiro I, Riera M, Herrera JA, Venturi I, Hernández Y, Fernández G, Pérez CL, Rodriguez JC, Fernández MD, Hernández-Balmaseda I, Fernández JR, Mesta F, Paz MT (2019) Chemoprotective effects of Ulva lactuca (green seaweed) aqueous-ethanolic extract against subchronic exposure to benzo(a)pyrene by CYP1A1 inhibition in mice. Phyther Res 33: 958-967. https://doi.org/10.1002/ptr.6289

16. SSA llah A-S, Abdel-Raouf N, El-Wazanani HA, Aref IA (2014) Antibacterial substances from marine algae isolated from Jeddah coast of Red sea, Saudi Arabia. Saudi J Biol Sci 21:57-64. https://doi.org/10.1016/j.sjbs.2013.06.001

17. Meenakshi S, Gnanambigai DM, Mozhi ST et al (2009) Total flavonoid and in vitro antioxidant activity of two seaweeds of Rameshwaram Coast. Glob J Pharmacol 3:59-62

18. Aleem AA (1993) The marine algae of Alexandria Egypt

19. Prieto P, Pineda M, Aguilar M (1999) Spectrophotometric quantitation of antioxidant capacity through the formation of a phosphomolybdenum complex: specific application to the determination of vitamin E. Anal Biochem 269:337-341. https://doi.org/10.1006/ abio.1999.4019

20. Al-Rifai A, Aqel A, Awaad A, ZA ALO (2015) Analysis of quercetin and kaempferol in an alcoholic extract of Convolvulus pilosellifolius using HPLC. Commun Soil Sci Plant Anal 46: 1411-1418. https://doi.org/10.1080/00103624.2015.1043454

21. Anjali KP, Sangeetha BM, Devi G, Raghunathan R, Dutta S (2019) Bioprospecting of seaweeds (Ulva lactuca and Stoechospermum marginatum): the compound characterization and functional applications in a medicine-a comparative study. J Photochem Photobiol B Biol 200:111622. https://doi.org/10.1016/j.jphotobiol.2019.111622

22. Raja R, Hemaiswarya S, Arunkumar K, Carvalho IS (2016) Antioxidant activity and lipid profile of three seaweeds of Faro, Portugal. Rev Bras Bot 39:9-17. https://doi.org/10.1007/s40415015-0200-8

23. Nabgan W, Abdullah TAT, Mat R et al (2016) Evaluation of reaction parameters of the phenol steam reforming over $\mathrm{Ni} / \mathrm{Co} \mathrm{On} \mathrm{ZrO} 2$ using the full factorial experimental design. Appl Sci 6. https://doi. org/10.3390/app6080223

24. Waszkowiak K, Gliszczyńska-Świgło A (2016) Binary ethanolwater solvents affect phenolic profile and antioxidant capacity of flaxseed extracts. Eur Food Res Technol 242:777-786. https://doi. org/10.1007/s00217-015-2585-9

25. Zuorro A, Lavecchia R (2013) Influence of extraction conditions on the recovery of phenolic antioxidants from spent coffee grounds. Am J Appl Sci 10:478-486. https://doi.org/10.3844/ajassp.2013.478.486

26. Bhebhe M, Füller TN, Chipurura B, Muchuweti M (2016) Effect of solvent type on total phenolic content and free radical scavenging activity of black tea and herbal infusions. Food Anal Methods 9: 1060-1067. https://doi.org/10.1007/s12161-015-0270-Z

27. Dorta E, Lobo MG, Gonzalez M (2012) Reutilization of mango byproducts: study of the effect of extraction solvent and temperature on their antioxidant properties. J Food Sci 77:80-88. https:// doi.org/10.1111/j.1750-3841.2011.02477.x

28. Liu Y, She XR, Huang J Bin, et al. (2018) Ultrasonic-extraction of phenolic compounds from Phyllanthus urinaria: optimization model and antioxidant activity. Food Sci Technol 38:286-293. https:// doi.org/10.1590/1678-457x.21617

29. Che Sulaiman IS, Basri M, Fard Masoumi HR, Chee WJ, Ashari SE Ismail M (2017) Effects of temperature, time, and solvent ratio on the extraction of phenolic compounds and the anti-radical activity of Clinacanthus nutans Lindau leaves by response surface methodology. Chem Cent J 11:54. https://doi.org/10.1186/s13065-017-0285-1

30. Abd-Rahim SN, Sulaiman A, Edama NA et al (2014) Factorial design analysis of a tapioca slurry saccharification process using encapsulated enzymes. BioResources 9. https://doi.org/10.15376/ biores.9.2.3361-3368

Publisher's Note Springer Nature remains neutral with regard to jurisdictional claims in published maps and institutional affiliations. 